'Department of Microbiology and Immunology, New York Medical College.

El autor declara no tener conflictos de interés. Trabajo no recibió financiamiento.

Recibido el 27 de mayo de 2018, aceptado el 22 de agosto de 2018.

Correspondencia a: Dr. Felipe C. Cabello Valhalla, NY 10595cabello@ nymc.edu

\section{El retablo de Isenheim: religión, arte y medicina}

\author{
FELIPE C. CABELLO ${ }^{1}$
}

\section{The Isenheim altarpiece: religion, art and medicine}

Northern Europe at the beginning of the $16^{\text {th }}$ Century was in turmoil as a result of religious and political dissention, epidemics of plague, syphilis, ergotism, and famine, and the threat of the Ottoman Empire. In Alsace, a fulcrum between Germany, France, Switzerland and the Netherlands, Grünewald painted his celebrated and complex altarpiece at Isenheim in a convent chapel of the Antonine religious order that kept a hospital for the care of patients suffering from ergotism, plague, syphilis and other illnesses. The ten paintings of this altarpiece convey a series of religious, medical and political meanings, with the scenes of the Crucifixion and the Resurrection being thought to play an integral part of the curative process. This was because patients could be soothed by comparing their suffering to that of Christ on the cross and could console themselves by the Resurrection. The portrait of Christ in the cross is astounding in its realism and naturalism. It represents, with great pathological veracity, a tortured body in agony, a break with previous traditional representations of this event. Impressive pathological detail is also given to a figure in the Temptation scene. The entire work is suffused with religious connotations provided by the composition, the forms and the richness and sophisticated use of colors. Although Grünewald's paintings are few and the facts of his personal life sparse, it is known he married a Jewish woman, supported the peasant revolts, and was probably a Lutheran in a Catholic area. While Grünewald is considered the epitome of a German artist, the universal projections of his art have influenced physicians and the artistic productions of many painters, writers, musicians and sculptors throughout the world.

(Rev Med Chile 2018; 146: 1050-1058)

Key words: History of Medicine; Pathology; Religion and Medicine; Therapeutics.
E n los períodos de Semana Santa, en que las estaciones radiales saturan el espacio con la música de J. S. Bach, banalizándola, es importante recordar cuanta originalidad musical y profundidad religiosa el compositor situó en sus numerosas creaciones ${ }^{1}$. Estas características de su obra se aprecian, por ejemplo, al escuchar los versos del coro de la Pasión según San Juan "Señor nuestro Dios (Herr!, unser Herrscher)", que con el sombrío trasfondo musical de los oboes y de los violines, conmueve y ayuda a visualizar la
Crucifixión de un cuerpo torturado ${ }^{1}$. Esta sección musical, según algunos musicólogos trasuntaría una relación dialéctica entre los dolientes que presencian la Crucifixión y la del hombre en la cruz mirando simultáneamente hacia la tierra y al cielo, con una mezcla de catástrofe y de triunfo, anunciando la futura Resurrección ${ }^{1}$.

Lo sombrío e inusual de la música Bachiana retrataría adecuadamente el sufrimiento del cuerpo de Cristo, lacerado y goteando sangre, que es elevado clavo a clavo a la cruz, teniendo solamente 
como trasfondo el murmullo triste de espectadores en duelo ${ }^{1}$. Sin embargo, el realismo artístico en la representación de la Crucifixión, tan bien reflejado en la música de Bach, tiene un antecedente aproximadamente 200 años antes en el famoso políptico de Isenheim pintado por Matthais Grünewald en los años 1512 a1516 2-8. En su representación de Cristo y de la Crucifixión, este políptico fractura drásticamente toda la tradición artística gótica medieval y del Renacimiento, especialmente del sur de Europa, acostumbrada a retratar este acontecimiento de una manera serena y con la imagen de Cristo esperando tranquilamente su muerte, haciendo abstracción de su sufrimiento y de su naturaleza corpórea y humana ${ }^{2-9}$.

En esta obra, Cristo crucificado se representa por primera vez en la historia de una manera realista y natural, con las lesiones patológicas cutáneas y musculares de un cuerpo que pareciera torturado extensivamente y que la tradición indica, las que Grünewald probablemente presenció en los cadáveres de los enfermos del hospital para el cual la pintura fuera comisionada ${ }^{2-8}$. Esta realidad patológica y el hecho de que el hospital perteneciente a la orden religiosa de San Antonio fuera dedicado al cuidado de enfermos de ergotismo ${ }^{2-13}$ confiere a esta obra, además de una gran significación estética y religiosa, una importante relevancia para la historia de la medicina ${ }^{2-15}$.

\section{El políptico de Isenheim}

En el villorrio de Isenheim, los monjes Antoninos tenían en su convento un hospital para atender a los enfermos que padecían de diversas dolencias, especialmente de ergotismo ${ }^{2,4,10,11,13,15}$. El superior del convento, el italiano Guido Guerci, comisionó el retablo para que los pacientes del hospital tuvieran un objeto devocional al cual dirigir sus plegarias implorando su curación, y al mismo tiempo pudieran encontrar consuelo de sus sufrimientos, comparándolos al sufrimiento de Cristo y al ver su esperanzadora Resurrección ${ }^{2,4,10,11,13,15}$. La magnitud de la obra, y su plétora de significados, limita la discusión de las diez pinturas presentes en ella. Solo me dedicare a discutir aquellas que considero importantes para la historia de la medicina, y que son la de la Crucifixión, la de la Resurrección y la de la Tentación de San Antonio ${ }^{2,4,10,11,13,15}$. La obra, que es de un tamaño gigantesco, con tres planos pintados al óleo y tempera sobre paneles de madera que se abren girando sobre bisagras, consta también de una predela inferior que se abre solamente en dos planos y de esculturas religiosas de madera en el centro del tercer plano ${ }^{2-15}$.

La pintura de la Crucifixión (Figuras 1 y 2) está en el centro del primer plano. La Resurrección (Figuras 3 b y 3 c) aparece expuesta a la derecha después de abrir el segundo plano. También a la derecha, después de exponer el tercer plano, encontramos la Tentación de San Antonio (Figuras 4 a y b), enmarcando a las esculturas de madera ${ }^{2-15}$. La Crucifixión, con el realismo brutal de las huellas de la tortura en el cuerpo de Cristo, y el retrato sin inhibiciones de su violenta agonía, imparte a esta una extraordinaria veracidad, aumentado así su significado religioso y médico ${ }^{2,4,10,11,13,15-17}$. El primero sería además amplificado por la distorsión generada por el pintor al romper la armonía entre los tamaños del enorme Cristo crucificado y la relativa pequeñez de las otras cuatro figuras en la pintura; San Juan Bautista a la derecha, María Magdalena y San Juan Evangelista consolando a la Virgen María a la izquierda (Figura 1) 2,4,10,11,13,15,17. Se suma el dramatismo que le confiere la presencia en el cuadro de San Juan Bautista, que ya había sido asesinado para la época de la Crucifixión, y que es entonces resucitado por el pintor, y por los expresivos rostros de dolor de María Magdalena y de la Virgen con sus implorantes manos de dedos largos y crispados (Figuras 1 y $2 \mathrm{a}$ ), y los dedos del Bautista señalando la agonía de Cristo (Figura 1) 2,4,10,11,13,15,17.

El fondo obscuro de la pintura, la cabeza inclinada de Cristo y sus labios azules, su piel herida y de un tono verduzco, sus manos y sus pies retorcidos y sangrantes, clavados a los irregulares maderos de la cruz, aumenta también la sensación de desolación y tragedia y presagian su extremo desenlace (Figuras 1 y 2 b, c, d) ${ }^{2-17}$. Un trágico equilibrio se logra por la composición tonal entre la albura de la vestimenta de la Virgen y la de los paños que cubren los genitales de Cristo y la de la piel del cordero a los pies del Bautista, que contrastan con los rojos variables y brillantes de los pliegues de las túnicas de los dos Juanes, de la Magdalena y de la sangre que emana del cuerpo de Cristo y del pecho del cordero a un cáliz dorado (Figura 1). El desamparo y agonía de la Crucifixión es balanceada por la imagen en la predela, en la base de la pintura, que representa a la Lamenta- 


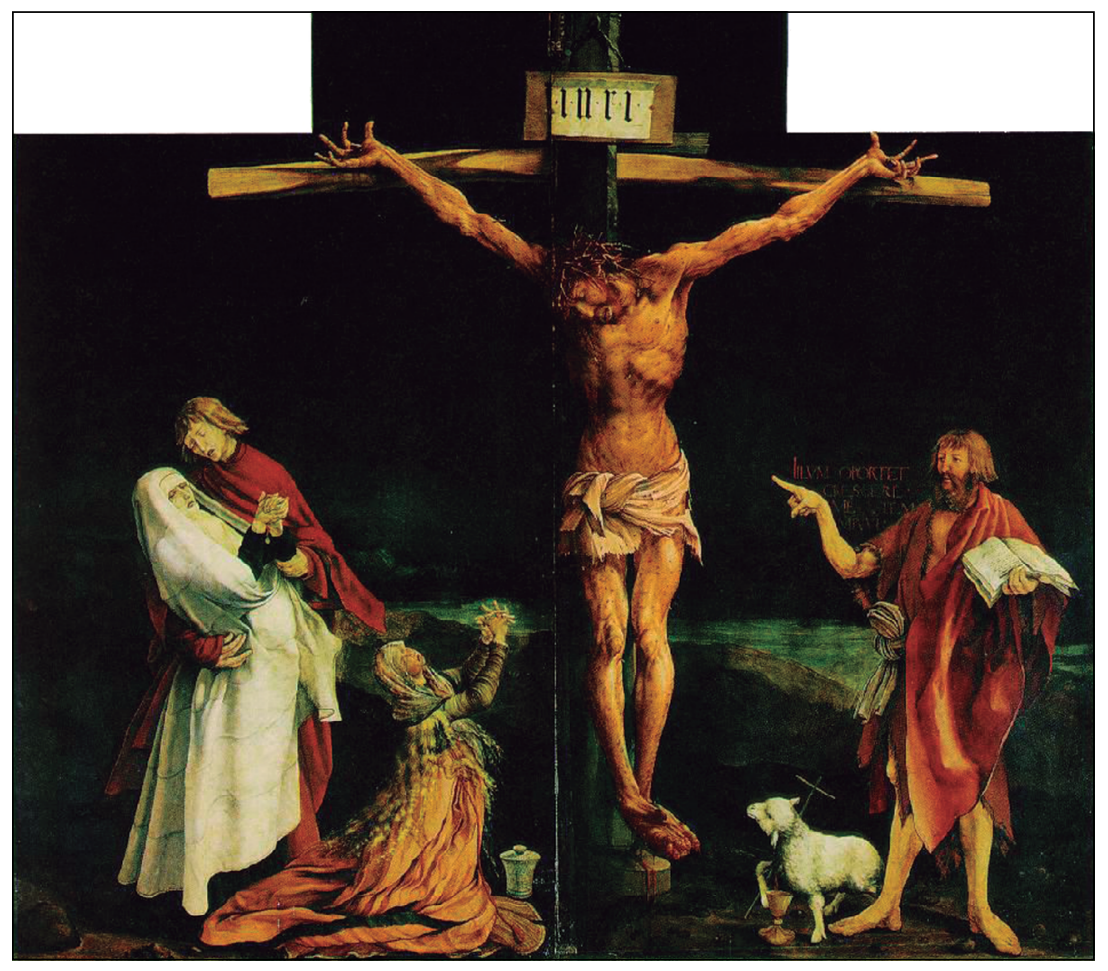

Figura 1. La Crucifixión.
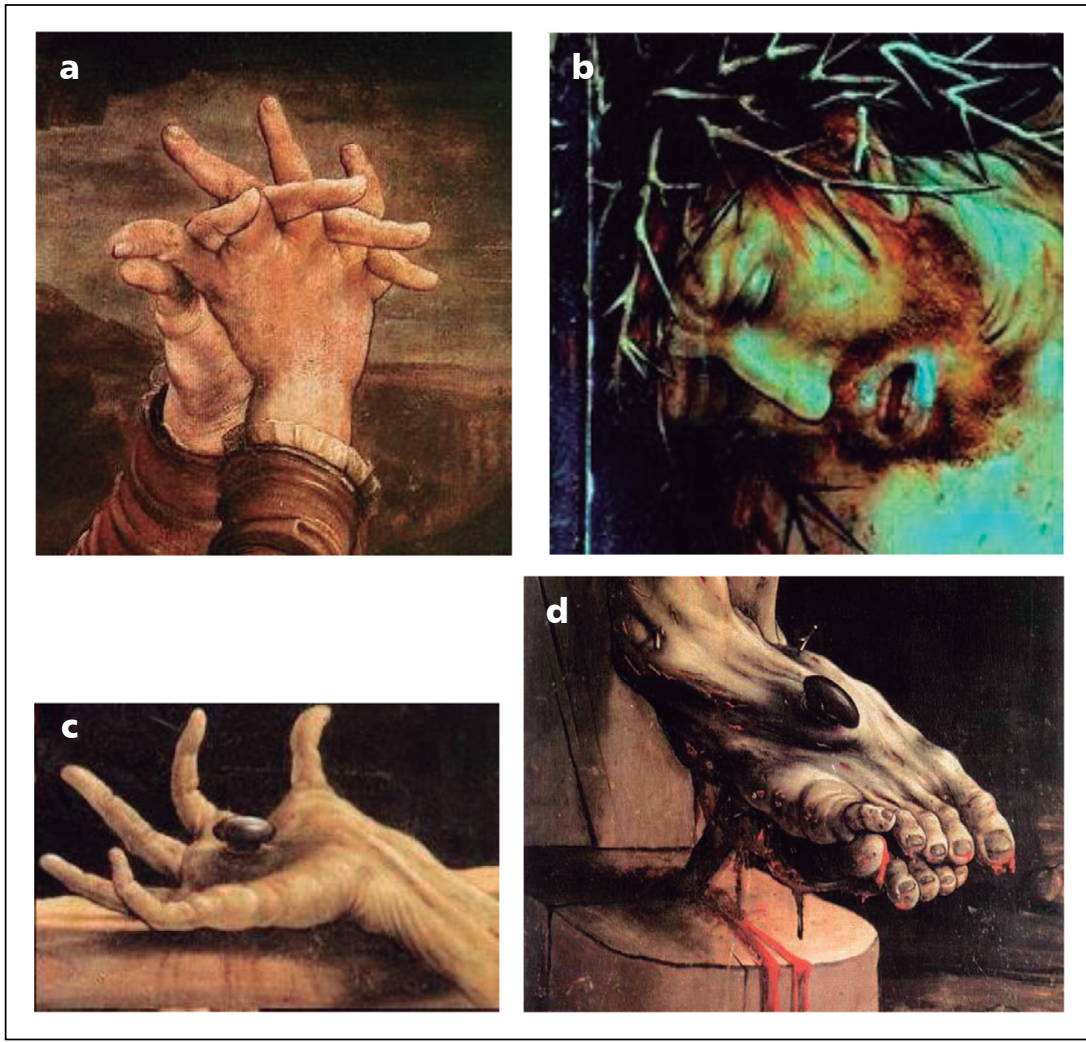

Figura 2. Detalles de la Crucifixión. 
ción, en la cual el cuerpo ya sin vida de Cristo está más allá del sufrimiento, adquiriendo su fisonomía la apariencia reposada de la muerte, que contrasta con sus heridas y con la imagen de dolor de las tres desconsoladas mujeres que preparan el cadáver para el entierro (Figura 3a) 2,4,10,11,13,15,17.

La Resurrección, es considerada también una de las obras maestras del arte pictórico mundial por su novedosa representación de Cristo en una forma y con colores que resaltan su triunfo sobre la muerte y que lo convierten en un mensajero victorioso de una nueva época (Figuras $3 \mathrm{~b}$ y $3 \mathrm{c})^{2-}$ ${ }^{15}$. Cristo destaca por su etérea representación, pintado como un ser fluido y volátil, planeando ágilmente sobre su tumba abierta, con sus brazos y pies extendidos mostrando los rojos estigmas de la Crucifixión, que contrastan con su nívea piel (Figura 3b $)^{2-15}$. Esta grácil representación de Cristo se diferencia drásticamente de las pesadas y obscuras imágenes de los tres soldados caídos delante y atrás de la tumba, empujados hacia el suelo por la energía y la luz que irradia de su cuerpo, que ha resucitado (Figura $3 \mathrm{~b})^{2-15}$. Grünewald también hace aquí un uso muy original de los colores, ya que, para representar la cabeza de Cristo y su aureola, usa una paleta de matices dorados cuya gradación hace desaparecer los contornos de ella en el espacio que la rodea, trasuntando una sensación de inmaterialidad (Figuras $3 \mathrm{~b}$ y $3 \mathrm{c})^{2-15}$. Las túnicas, rojas y azules y el blanco paño genital cuelgan del cuerpo de Cristo como si fueran atraídos por la gravedad y abandonados por la ascensión rápida de su cuerpo flotando en el aire, aumentando con esto la impresión espectral y de otro mundo

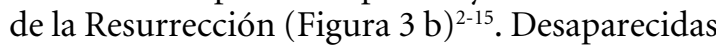
las lesiones cutáneas, la cara sufriente, las manos crispadas, el color verduzco de la piel y los chorros de sangre, el cuerpo de Cristo representa en esta Resurrección claramente el dominio de la vida sobre la muerte y de la salud sobre la enfermedad ${ }^{2-17}$.

En el examen de la tercera pintura, La tentación de San Antonio (Figuras 4a y b), me referiré
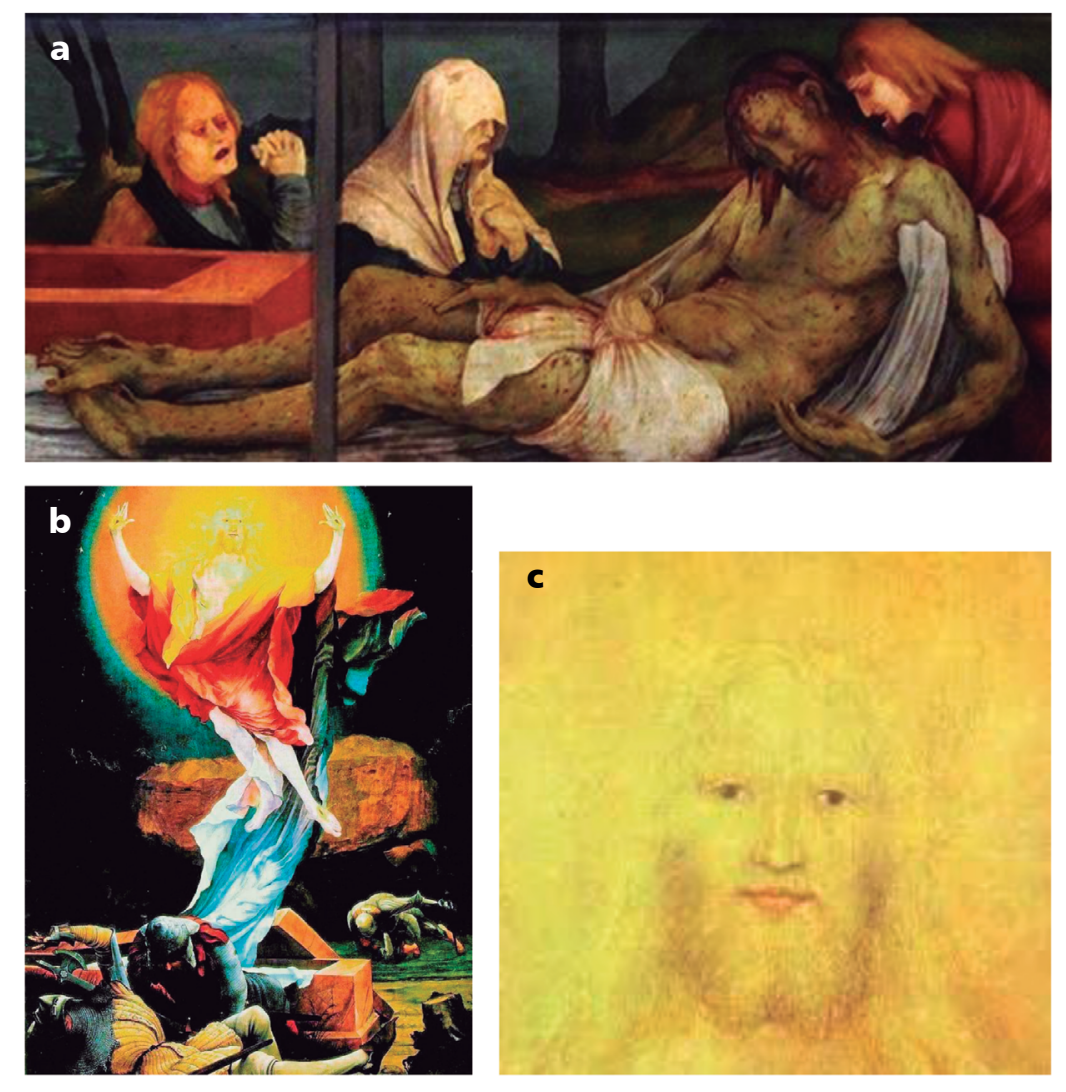

Figura 3. Predela con la Lamentación, la Resurrección y detalle. 
especialmente a la figura presentada en el ángulo izquierdo inferior del cuadro, ya que ella pareciera ser importante para esta presentación relacionada con la medicina (Figura 4 b) ${ }^{2-15}$. Algunos críticos piensan que esta figura es la de un demonio más asaltando a San Antonio, el que se ubica en el centro de la figura, embestido por ellos ${ }^{2-17}$; otros la interpretan como a un ser humano enfermo, presentado lesiones cutáneas, hemorrágico necróticas y purulentas, con cierta similitud a las lesiones pintadas por Grünewald en la piel de Cristo crucificado $^{2-15}$. El tinte verduzco de su piel también lo asemeja a Cristo. Sin embargo, su pie derecho pareciera más bien representar la extremidad de un ave palmípeda con los dedos unidos por membranas, lo cual lo alejaría de lo humano (Figura $4 \mathrm{~b})^{2-15}$. Sin lugar a dudas el pintor ha representado aquí a un individuo muy afligido por su enfermedad y, debido a ella, en una situación extrema, ya que incluso su brazo izquierdo pareciera estar amputado a nivel de la muñeca (Figura $4 b)^{2-15}$. La interpretación personal del observador decidirá si el pintor representa aquí a un ser humano enfermo o a un demonio. El autor nos muestra en él nuevamente su ilimitada imaginación y destreza al pintar los demonios asaltando al santo, los que manifiestan los más variados atributos zoológicos, incluyendo cuerpos y escamas de reptiles, plumas y picos de pájaro, dentaduras de carnívoros y bocas de peces (Figura $4 \mathrm{a})^{2-15}$, encarnado todo esto en una novedosa y bizarra composición de características pavorosas, que con un manejo del color y de la forma, altamente originales e impactantes, le imparten a esta representación de la Tentación gran espectacularidad (Figuras $4 \mathrm{a} \mathrm{y} \mathrm{b}^{2-15}$. Este breve análisis indica que en los tres planos del retablo de Isenheim, Grünewald representó imágenes relacionadas con la enfermedad, la vida y la muerte, como correspondería a una comisión pictórica para la capilla de un convento en un hospital ${ }^{2,11,15,18}$.

\section{El retablo y su relación con la medicina}

En la época en que esta obra fue pintada, el norte de Europa, incluyendo la región en que se encuentra este retablo, sufría de epidemias de peste, hambrunas, el azote del ergotismo y también comenzaba a aparecer de manera epidémica la sífilis, introducida esta última desde las Américas ${ }^{2,3,10,12,19,20}$. Diferentes autores han asignado la representación de algunas de estas enfermedades, incluyendo la sífilis, en las lesiones del cuerpo de Cristo y de la figura discutida en la Tentación ${ }^{2,10,12,15,19}$, sin embargo el contexto
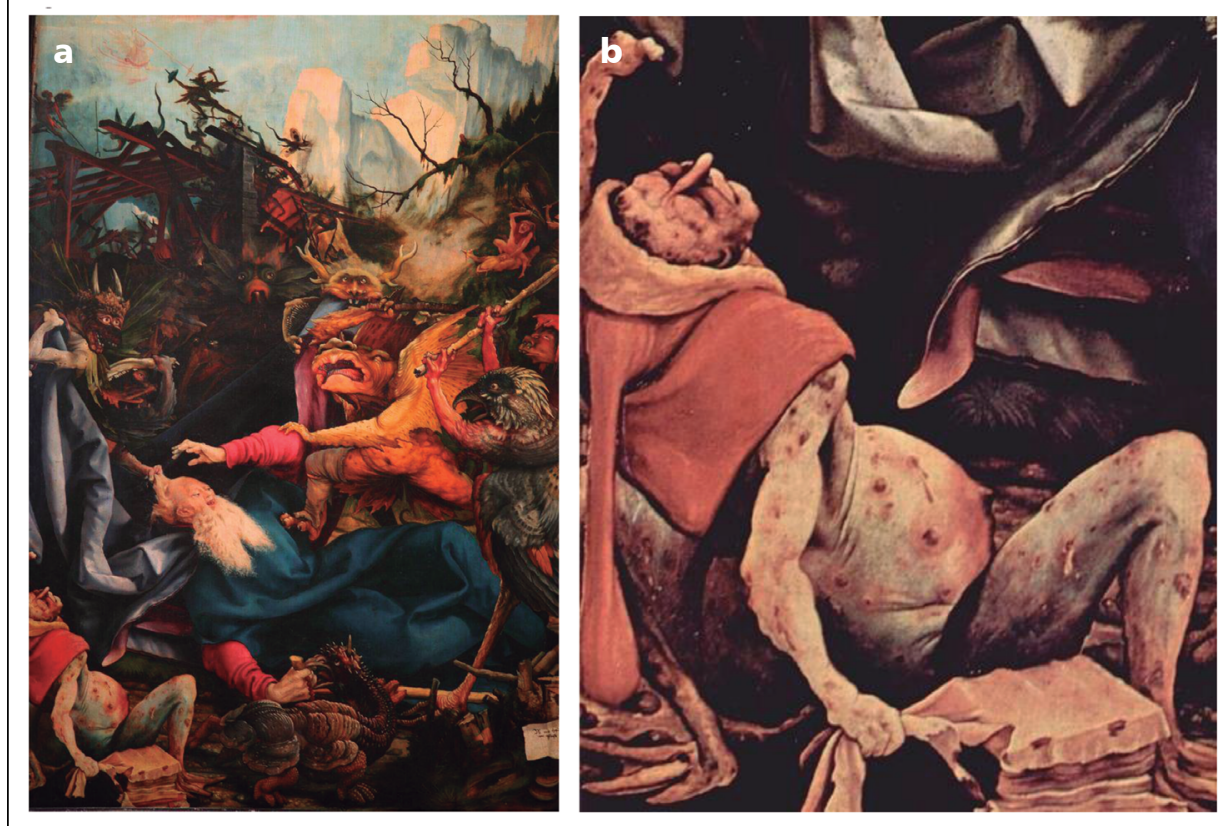

Figura 4. La Tentación de San Antonio y detalle. 
histórico indica que ellas corresponden a manifestaciones cutáneas de ergotismo ${ }^{2,10,11,12,15,20-25}$. Las manifestaciones del ergotismo son muy variadas e incluyen síntomas y signos cutáneos, neurológicos, intestinales y psiquiátricos que son el resultado de una vasoconstricción generalizada, que puede terminar con necrosis de los tejidos y de los órganos afectados, especialmente gangrena seca de las extremidades y de sus apéndices, los cuales se atrofian y terminan por auto cercenarse o deben ser amputados (Figura $4 b)^{2,10,11,12,15,20-25}$. La enfermedad también se acompaña de dolores lancinantes, de convulsiones y de alucinaciones, como la sensación de hormigueo debajo de la piel y caprichosas alucinaciones cromáticas ${ }^{2,10,11,12,15,20-25}$. Los dolores lancinantes, referidos como verdaderas quemaduras internas, junto con las lesiones tegumentarias, dio a esta enfermedad en la Edad Media el nombre de fuego sagrado (ignes sacer), o fuego de San Antonio, porque se creía que la protección de dicho santo la aliviaba y cura$\mathrm{ba}^{2,10,11,12,15,20-26}$.

Los síntomas y signos de la enfermedad se deben a la ingestión de pan elaborado con harina de centeno, o a la de semillas de este cereal, contaminadas con el hongo Claviceps purpurea, llamado también el cornezuelo del centeno, hongo que contiene una serie de alcaloides como la ergotamina y otros similares al ácido lisérgico ${ }^{21-28}$. Los alcaloides son metabolitos secundarios del hongo que actúan como agonistas de neurotransmisores como la epinefrina y la serotonina, interactuando con los receptores de estos, y son aún usados hoy en día en la terapia de la migraña y el sangrado uterino postparto ${ }^{21-28}$. Los suelos del norte de Europa eran pobres y, junto con el clima lluvioso y frio, favorecían el cultivo del centeno sobre otras gramíneas como el trigo ${ }^{22,23,29}$. Además, la humedad favorecía el parasitismo del centeno por el cornezuelo ${ }^{22,23,29}$. De acuerdo a algunos autores, Grünewald habría incluso deseado representar en su cuadro las coloridas alucinaciones del ergotismo con el uso de una gama de brillantes e inusuales colores, como se aprecia en la Resurrección y la Tentación ${ }^{2,10-13,25}$. El que en otra imagen de este retablo -la de San Antonio y Pablo, no discutida aquí, el pintor incorpora al frente de ella una serie de plantas medicinales como la verbena y el llantén usadas en baños para tratar esta enfermedad, le agrega también significado médico a la obra ${ }^{2,11,13}$.

\section{¿Quién fue Grünewald?}

De este artista, contemporáneo de A. Dürer, se conoce muy poco. Su producción pictórica es más bien reducida, y fuera del retablo comentado, ha sido de limitada difusión ${ }^{2,3-7,11,13,10,30-33}$. Por ejemplo, hasta mediados de; Siglo XVII se había creído que las pinturas de Isenheim eran de A. Dürer y solamente el trabajo de J. Von Sandrat en 1675, un historiador de la pintura alemán, demostró que ellas eran de la mano de Grünewald, y que este era un pintor llamado realmente Mathis Gothart Nithart nacido en la ciudad de Würzburg, en Franconia en 1480, y que habría fallecido en Halle en $1528^{2,3-7,11,13}$. Probablemente además de pintar, Grünewald (Gothart Nithart) hacia labores de diseñador e ingeniero constructor, habiendo estado a cargo de la reconstrucción del palacio de Aschanffenburg en Bavaria y habría sido un artífice en la producción de pigmentos para pinturas, lo que explicaría en parte su gran

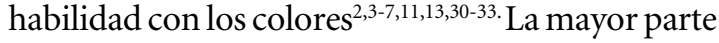
de su vida habría transcurrido en las regiones del sur de Alemania, como lo sugiere la influencia de esta región en su obra, ya que ha sido señalado que sus paisajes son netamente del sur de ese país, como lo son también de esa región el perfil y la cara de los personajes por él pintados ${ }^{2,3-7,11,13,30-33}$. La producción del pintor pareciera corresponder a una obra totalmente original, sin precursores o seguidores, que como se ha dicho representa a un genio excepcional, que pinta en su propio lenguaje y que pareciera intentar representar la antítesis de lo habitual ${ }^{2,3,5,6,11,12,31,33}$.

Recientemente, otro gran creador alemán prematuramente fallecido, el escritor W. G. Sebald (1944-2001), escribió un largo poema biográfico acerca de Grünewald titulado "Como la nieve en los Alpes” (2001), que dado sus detalles pareciera estar basado en investigaciones que Sebald realizo acerca de la vida del pintor ${ }^{33}$. De acuerdo a estas, el pintor se habría casado con una joven judía conversa de Frankfort de gran belleza mucho más joven que él, con la cual habría tenido un hijo. Este habría fallecido en la adolescencia, y ella habría terminado hospitalizada muy joven en un asilo psiquiátrico, muriendo después que el pintor ${ }^{33}$. El haberse casado con una judía, las tragedias de su vida, el realismo impactante de sus pinturas, sus simpatías por Lutero y sus doctrinas, y su parcialidad por las revueltas de campesinos contra 
los príncipes y los obispos, le habría dificultado encontrar trabajo en el sur de Alemania y lo habría convertido en un migrante. De allí lo fragmentado de su registro histórico y la dispersión de su obra $^{2,10,11,30,33}$. En su investigación, Sebald encontró en diversos museos de Europa y de EE.UU. dibujos que parecieran ser autorretratos de Grünewald, y opinó que el pintor se autorretrató en sus pinturas y que incluso su rostro aparece en un cuadro pintado por Holbein el joven, exhibido en un museo de Basilea ${ }^{33}$. Destaca Sebald también el deseo del pintor de representar en sus cuadros a individuos conocidos de él, entre los que sobresale su contemporáneo, el inimitable y legendario escultor en madera T. Riemenschneider, que por apoyar, al igual que Grünewald, las revueltas campesinas ${ }^{33}$ terminara torturado y con sus manos destrozadas por el verdugo del obispo de Würzburg. Sin lugar a dudas, el reconocimiento de la originalidad de Grunewald y lo novedoso de su obra es un fenómeno moderno, que comenzó en Europa hacia fines del Siglo XIX y que coincidió con el nacimiento en ese continente de la historia del arte como una disciplina intelectual ${ }^{2,10,11,30,33}$. Desde esa época, el interés por la obra del pintor se ha mantenido vivo y ha estimulado las inquietudes intelectuales de una serie de artistas, escritores y médicos no solamente en Alemania y Francia, pero en otros países de Europa y últimamente en los EE. UU., como lo acreditan una serie de estudios en inglés acerca de su obra ${ }^{2,10,11,30}$.

\section{El poliptico de Isenheim, la cultura alemana y la universal}

La resistencia de esta pintura por más de 500 años a numerosas vicisitudes es un tributo al abanico de sentimientos que es capaz de despertar, y también constituye un homenaje al genio y al arte de su pintor ${ }^{2,3,5,10-12,15,33}$. La obra sobrevivió la Reforma de Lutero durante la cual hubo una destrucción de imágenes religiosas en todo el sur de Alemania y en el norte de Francia y en Suiza $^{2,3,5,10-12,15 .}$ En 1794, durante la Revolución Francesa, fue salvada de la destrucción de iconos religiosos llevada a cabo por los revolucionarios de la época, quienes la sacaron del convento de Isenheim para protegerla ${ }^{2,3,5,10-12,15}$. Al comienzo de la Primera Guerra Mundial fue transportada a un museo de Münich por el gobierno alemán para salvarla de una potencial destrucción bélica en el frente de Alsacia ${ }^{2,3,5,10-12,15}$, despertando, al ser exhibida, grandes sentimientos patrióticos $2,3,5,10-12,15$. Después de la primera guerra la pintura fue devuelta a Francia al museo UnterLinden en la ciudad de Colmar, cerca de Isenheim, de donde nuevamente fue sacada por el ejército alemán en la Segunda Guerra para protegerla y en donde después de ser nuevamente devuelta permanece hasta hoy día ${ }^{2,3,5,10-12,15,34-36}$. Durante todas estas vicisitudes la pintura ha sido vista por el público, entre ellos una serie de intelectuales y artistas que después de la visita al museo han plasmado en sus obras la influencia de ella ${ }^{2,3,5,10-12,15,34-36}$.

La pintura fue comentada por los Drs. J. M. Charcot y P. Richet durante el Siglo XIX, los que atribuyeron, equivocadamente a mi juicio, las lesiones del individuo en la Tentación a la sífilis (Figura $4 b)^{2,10,19}$. La obra es aún imitada hoy en día en el ámbito médico, como ha sucedido recientemente con el Altar de Keiskamma, que fuera construido como un testimonio de la batalla contra el SIDA en Sud África ${ }^{37}$. Aspectos del valor estético, ético, político y médico del altar de Isenheim han sido comentados por escritores tan variados como J. K. Huysmans, T. Mann, A. Schweitzer, E. Canetti, R. M. Rilke y S. Zweig, el sociólogo y critico W. Benjamin y el compositor P. Hindemith ${ }^{2,12,15,38}$. Este último usó la versión novelada de la vida de Grunewald como inspiración para su famosa y original ópera y sinfonía titulada "Matthis der Maler (Matias el pintor), la que dedicó a Grunewald definiéndolo como "el gran artista que Alemania jamás haya tenido" 38 . Canetti dijo que la pintura era "un recuerdo de las cosas horribles con que los humanos afligen a otros humanos... Todo el horror que nos espera a la vuelta de la esquina está anticipado en ella" 2 . La obra también inspiró a pintores como A. Böcklin y a los alemanes expresionistas como F. Marc, M. Bekmann E. L. Kirchner y E. Nolde, a los rupturistas y antibélicos Otto Dix and G. Gröz, y también a P. Picasso y a H. Matisse, y al estadounidense Jaspers Johns, quienes usaron al políptico como modelo para sus propias pinturas ${ }^{2,16}$.

Dado su realismo innovador y la identificación del pintor con movimientos políticos y religiosos antiautoritarios, el altar que ya tenía un matiz político cuando fue pintado por Grünewald, ha sido también objeto de las diferencias franco alemanas respecto a la soberanía de Alsacia ${ }^{2,12,33,34}$. En el período del nazismo en Alemania lo lógico hubiese 
sido que este pintor y su obra considerada tan alemana hubiese sido exaltada por el régimen. Sin embargo, esto no ocurrió porque el gran estudioso de Grünewald en esa época fue un historiador del arte judío, W. Fraenger, cuyos libros, incluyendo un estudio de Grunewald (1938) fueron quemados por los nazis ${ }^{2,33,34}$. El hecho de que el pintor se hubiese casado con una judía tampoco lo hacía, para esa época tenebrosa, un ejemplo de pureza racial y un historiador del arte favorito de Hitler, W. K. Zülch, en la biografía del pintor $(1938)^{33}$ ignoró este matrimonio. Hindemith nunca pudo representar su famosa ópera en Alemania, ya que no aceptó modificarla para disminuir en ella, a petición de J. Goebbels and H. Göering, la simpatía que Grünewald demostrara para con las rebeliones campesinas de su época y que estos tildaron de bolchevismo musical ${ }^{2,38}$. En resumen, como dice G. Sebald en el poema citado, "De esta manera Grünewald, de forma silenciosa, consciente y con su pincel, representó los lamentos, los gemidos, el lloriqueo y el doloroso alarido de un espectáculo patológico, al cual él, su arte y su época pertenecían" ${ }^{33}$, y como ha sido señalado repetidamente, este significado de la pintura continúa vigente aun en nuestra época y de allí su interés, actualidad y universalidad ${ }^{2,20}$.

Agradecimientos: La composición del artículo se benefició con las frecuentes conversaciones sobre la cultura alemana con mi esposa, Lieselotte Aron H., y de las múltiples discusiones con mis colegas Drs. S. Newman, D. Köhl y H. Godfrey sobre arte y medicina. Mis ya desaparecidos compañeros y amigos del Liceo de Ancud, Chiloé, Eric y Gustavo Altaner K., su acogedora familia y las familias de descendencia alemana de esa ciudad me introdujeron tempranamente y con cariño a las costumbres de sus antepasados y potenciaron mi interés por la historia de Alemania. Escribir el artículo habría sido imposible sin la incomparable ayuda del altamente profesional y atento personal de la biblioteca del New York Medical College y de la gran institución bibliográfica que son los préstamos inter bibliotecarios.

\section{Referencias}

1. Rose A. Bach's Holy Dread. The New Yorker. 2017. January 2.

2. Hayum A. The Isenheim Altar Piece. God, medicine and the painters's vision. Princeton U. Press. Princeton. NJ. 1989.

3. Smith J C. Dancing with death in The Northern Renaissance. Phaidon Press, Inc. Books. New York. NY. 2006. Pp. 197-238.

4. Mellinkoff R. The Devil at Isenheim. Reflections in popular belief in Grünewald Altar Piece. U. of California Press. Berkeley. CA. 1988.

5. Nochlin L. Mathis at Colmar. A visual confrontation. Red Dust, Inc. New York. NY. 1963.

6. Gombrich E H. The New Learning Spreads. Germany and the Netherlands, early sixteenth Century in The Story of Art. Phaidon Books. New York. NY. 1995. Pp. 257-71.

7. Zuffi S. Matthias Grünewald in European Art of the Sixteen Century. The J. Paul Getty Museum. Los Angeles. CA. 2005. Pp. 309-11.

8. Levey M. High Renaissance. Penguin Books. New York. NY. 1987.

9. Murray P y L. The Art of the Renaissance. Thames and Hudson. New York. NY. 1963.

10. Monick E. Evil, Sexuality and Diseases in Grünewald Body of Christ. Spring Publications. Dallas. TX. 1993.

11. Cork R. The Burning Sickness in The healing presence of art. Yale U. Press. New Haven. CT. 2012. Pp. 73-85.

12. Huysmans, JK. The Grünewalds in the Colmar Museum. Translated by R. Baldick. Phaidon Press. New York. NY. 1958.

13. El Retablo de los Ardientes. Matthias Grünewald. You Tube. https://www.youtube.com/watch?v=tmhe-iZD$3 \mathrm{mM}$.

14. Battin J. Saint Anthony's Fire or gangrenous ergotism and its medieval iconography. Hist Sci Med 2010; 44: 373-82. PubMed PMID: 21598563.

15. Snyder J. The Isenheim Altarpiece and Matthias Grünewald en Northern Renaissance Art. H. N. Abrams. N. York. NY. 1986 Pp. 348-56.

16. Stieglitz A. The Reproduction of Agony: Toward a Reception-History of Grünewald's Isenheim Altar after the First World War. Oxford Art Journal 1989; 12: 87-103.

17. Baldwin R. Anguish, Healing, and Redemption in Grünewald's Isenheim Altarpiece. Sacred Heart University Review. 2010. 20: Iss. 1 , Article 5.

18. Donadio E. Painting for patients: Grünewald's Isenheim Altarpiece. Med Herit 1985; 1: 448-54. PubMed PMID: 11620872.

19. Charcot JM y Richet P. Le difformes et les Malades dan l'Art. Lecrosnier et Babe. París. 1889.

20. Berger J. Between Two Colmars en Selected essays. G. Dyer Ed. Vintage International. New York. NY. 2001. Pp. 325-9. 
21. Stockman R. The Cause of Convulsive Ergotism. J Hyg (Lond) 1934; 34: 235-41. PubMed PMID: 20475230; PubMed Central PMCID: PMC2170805.

22. van Dongen PW, de Groot AN. History of ergot alkaloids from ergotism to ergometrine. Eur J Obstet Gynecol Reprod Biol 1995; 109-16. PubMed PMID: 7641960.

23. Alm T, Elvevåg B. Ergotism in Norway. Part 1: The symptoms and their interpretation from the late Iron Age to the seventeenth century. Hist Psychiatry. 2013; 24: 15-33. doi: 10.1177/0957154X11433960. PubMed PMID: 24572795.

24. Alm T, Elvevåg B. Ergotism in Norway. Part 2: The symptoms and their interpretation from the eighteenth century onwards. Hist Psychiatry 2013; 24: 131-47. doi: 10.1177/0957154X11433961. PubMed PMID: 24573255.

25. Kierulf H. Ergotism in Bosch and Grünewald. Nouv. Presse Med 1982; 11: 2803-9. French. PubMed PMID: 6757856.

26. Meggs WJ. Epidemics of mold poisoning past and present. Toxicol Ind Health 2009; 25: 571-6. doi: 10.1177/0748233709348277. Epub 2009 Oct 6. Review. PubMed PMID: 19808743.

27. Van Zwanenberg D. A 'singular calamity'. Med Hist 1973; 17: 204-7. PubMed PMID: 4578418; PubMed Central PMCID: PMC1081452.

28. Chassar Moir J. Ergot: From "St. Anthony's Fire" to the isolation of its active principle, ergometrine (ergonovine). American Journal of Obstetrics \& Gynecology. 1974; 120: 291-6.
29. De Costa C. St Anthony's fire and living ligatures: a short history of ergometrine. Lancet 2002; 359: 1768-70. PubMed PMID: 12049883.

30. Sauerlander W. Mysteries of a Masterpiece. The New York Review of Books. 1991. May 30.

31. Meisler S. A Masterpiece Born of Saint Anthony's Fire. The Smithsonian. 1999. August 31.

32. Jone J. Hidden Horror, The Guardian. 2007. December 12.

33. Sebald W G. ...As the Snow in the Alps en After Nature. Modern Library. New York. NY. 2001. Pp. 1-37.

34. McCouat $P$. The Isenheim altarpiece: nationalism, nazism and degeneracy. J of Art in Society. http://www. artinsociety.com/the-isenheim-altarpiece-pt-2-nationalism-nazism-and-degeneracy.html.

35. Elkins J. Seeing bodies en The Object Stares Back. On the nature of seeing. Harvest Book. Harcourt, Inc. New York. NY. Pp. 126-59.

36. Bogousslavsky J. Charcot and art: from a hobby to science. Eur Neurol 2004;51:78-83. Epub 2004 Jan 28. PubMed PMID: 14752213.

37. Hinze BA. Saint Anthony's Fire and AIDS: Two Altarpieces and the Oft-Forgotten Goals of Medicine. Virtual Mentor 2007; 9: 455-9. doi: 10.1001/virtualmentor.2007.9.6.mhum1-0706. PubMed PMID: 23218055.

38. Bruhn S. Aesthetic Symbiosis and spiritual quest: Grünewald's Isenheim Altarpiece in Hindemiths's Opera Mathis der Maler. M. Kronegger (ed.). Analecta Husserliana 2000; 63: 17-51. 